\title{
FLOW MEASUREMENT ON HOT WATER LiNES AT Geothermal Power Plant Using Ultrasonic Method
}

\author{
Jan Ilko, Miroslav Rusko, Christian Halper, Milan Majernik \& Stefan Majernik
}
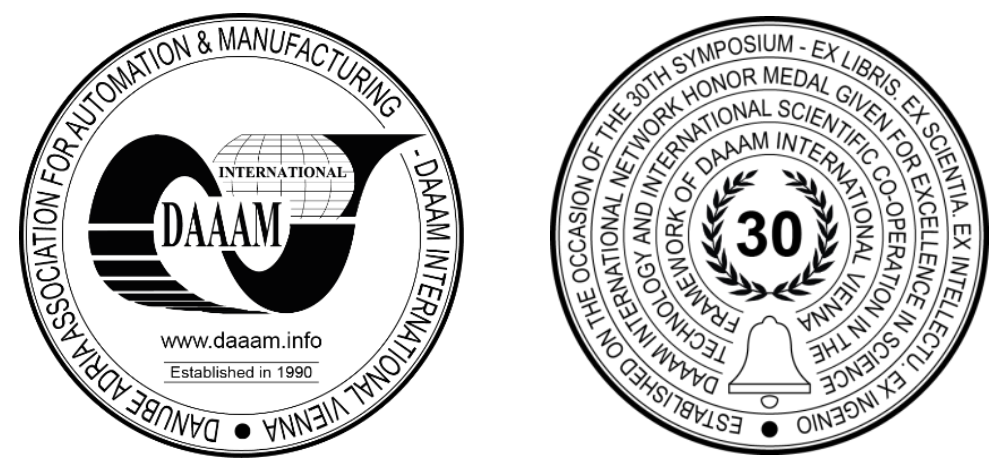

This Publication has to be referred as: Ilko, J[an]; Rusko, M[iroslav]; Halper, C[hristian]; Majernik, M[ilan] \& Majerník, S[tefan] (2020). Flow Measurement on Hot Water Lines at Geothermal Power Plant Using Ultrasonic Method, Proceedings of the 31st DAAAM International Symposium, pp.0341-0347, B. Katalinic (Ed.), Published by DAAAM International, ISBN 978-3-902734-29-7, ISSN 1726-9679, Vienna, Austria

DOI: $10.2507 / 31$ st.daaam.proceedings.048

\begin{abstract}
The aim of the article is the measurement of media flow on a geothermal plant at a temperature of $160{ }^{\circ} \mathrm{C}$, before and after gas separator during real conditions. The ultrasonic flow monitoring method for the measurement was used. Because of very high amount of gas in the line and high temperature of the media the F601 portable ultrasonic flow meter with extended temperature sensors was chosen. Measurement was done at three points, two of them before and one after the gas separator. The results are useful for projecting of new plants, improvements, designing the flow monitoring instrumentations of mentioned technological points or other purposes. The goal of this study is to implement the progressive non-invasive measurement method instead of inductive sensors standardly used.
\end{abstract}

Keywords: Geothermal plant; Flow monitoring; Non-invasive method; Ultrasonic flow meter.

\section{Introduction}

In context of the current socio-economic activities of society, the solution of issues and problems related to environmental pollution is becoming more and more popular. Environmental degradation not only affects densely populated areas, heavy industrial pollution etc., but often affects areas that do not directly attack environmentally unsuitable activities. One of the important pro-environmental oriented activities is the use of geothermal energy, which has considerable potential to help reduce the negative impacts of current anthropogenic activities.

The technical aspects of the use of geothermal energy have their specifics. The aim of the article is the flow measurement of a medium in a geothermal power plant at a temperature of $160{ }^{\circ} \mathrm{C}$, before and after a gas separator in real conditions. Flow is one of the most measured parameters nearby temperature and pressure in technological processes. Such process can include several flow meters or many of them, depending on the character and size of technology. There is a wide variety of flow monitors on market based on different measuring methods. In case of high amount of measuring points, is the main factor for choosing a type of flow meter the price, as if the precision is lower or lifetime of the flow meter is shorter. Many times, there are applications with higher requirements for high precision and reliability of the flow monitors, on a market. In such cases, there are flow meters with more complicated technology and algorithm in behind to fulfil this criteria. In this study is described flow measurement on geothermal plant using the ultrasonic flow meter F601 on existing pipelines at the outlet of the well, before and after the gas-separator. 


\section{Theory}

Heat is a form of energy [1] and geothermal energy provides continuous base-load power with minimal visual and other environmental impacts. Geothermal systems have a small footprint and virtually no emissions, including no carbon dioxide. Geothermal energy has significant base-load potential, requires no storage, and, thus, it complements other renewables - solar (CSP and PV), wind, hydropower - in a lower-carbon energy future [2],[26]. Geothermal steam frequently contains small amounts of entrained liquid water, non-condensable gases such as $\mathrm{CO}_{2}$, and other constituents such as silica [3]. Some impurities, such as $\mathrm{NaCl}$, may be present as dissolved species in the liquid or as solid particulate [4]. Diagram of a geothermal power plant is shown in Figure 1. Geothermal power does not require the burning of any fossil fuels. The hot water or steam used is returned to the ground after it is used where it can be used again, which makes it a renewable energy source as well [5].

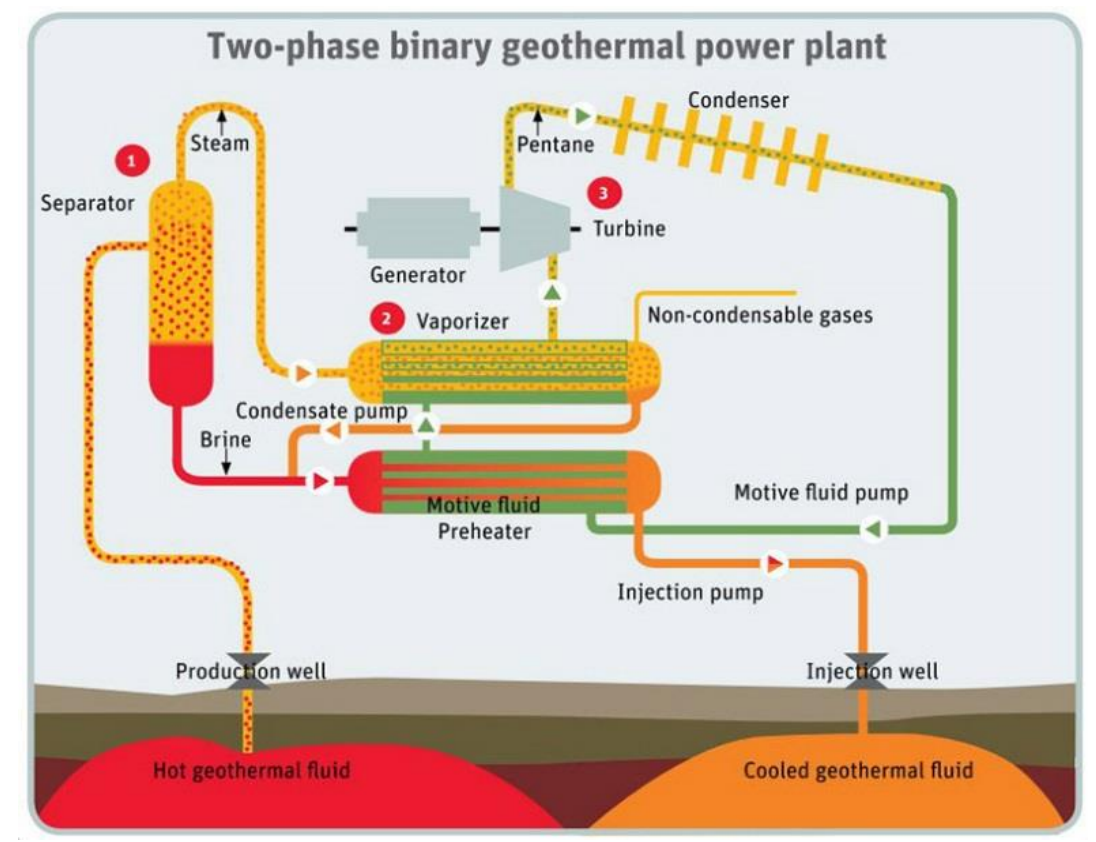

Fig. 1. Geothermal power plant [6]

\section{Materials and Methods}

\subsection{General and special requirements}

Diagnostics of technological processes is one of the primary management tools in the organization [7]. The monitoring and control system requires that the information coming from the measurement instruments to be highly reliable, as plant production depends upon it [27]. For that reason, all the measurement instruments from the separation stations and producing wells (the same for the rest of the plant) require special features which have to be specified during the purchasing processes. These special requirements must be according to the special conditions in the geothermal field and to the high quality standards that guarantee the reliability needed [8].

\subsection{Instruments and equipment}

The power generation industry largely depends on feed water and hydrocarbon fuels to generate electricity. The flow of such liquids, gases, or a mixture of both must be monitored accurately to keep the entire system operating in an efficient manner. To achieve precise flow monitoring, power plants require reliable and responsive flow measurement systems to measure and verify liquid/gas flow [9]. Among the many different measurement techniques available, the orifice plate stands out for its simplicity, low cost, and the ability to provide real time measurements [10]. The ultrasonic flow meter provides numerous advantages over other types of flow measuring meters. The main advantage provided is ultrasonic measurements are non-invasive. The flow of fluid is measured by clamping a set of transducers on a pipe. Because in most cases the transducers are placed on the outside, they do not get in contact with the fluid [11].

Following equipment was used for the flow measurement:

- FLEXIM F601 with $1 \mathrm{MHz}$ sensor - extended temperature version up to $200{ }^{\circ} \mathrm{C}$,

- FLEXIM wall thickness probe. 
Ultrasonic clamp-on flow meters are widely used in many areas of industry. One of their key advantages is that the flow measurement takes place contactless [12]. A pair of ultrasonic measuring heads is placed onto the outside of a tubing. By means of a measuring transducer, an ultrasonic pulse is generated alternately in both measuring heads and, after having passed through the tube wall and the medium in the tube, is received by the respectively other measuring head [13]. With clamp-on flow meter devices using the transit time difference method, the difference between two sound signals traveling with or against the direction of flow is measured, and the volume flow is calculated from this difference [14].

FLUXUS ${ }^{\mathrm{TM}}$ instruments feature an exceptionally robust dual- $\mu \mathrm{P}$ technology core together with the latest digital signal processing. They produce stable and reliable results even under the most difficult application conditions. FLUXUSTM measurement algorithm automatically adapts to the varying application conditions. Its very high measurement rate of 1000 measurements per second allows a real time statistical analysis [15].

\section{Practice}

The measurements were done on two points. The first one was directly at the piping of the well (Figure 3) and the second measurement was located at the outlet of the separator (Fig. 4). At first the measurement point must be prepared and cleaned for the sensor mounting. There are several possibilities of the mounting using special brackets designed for fast and simple sensor positioning on the pipe (Fig. 2).

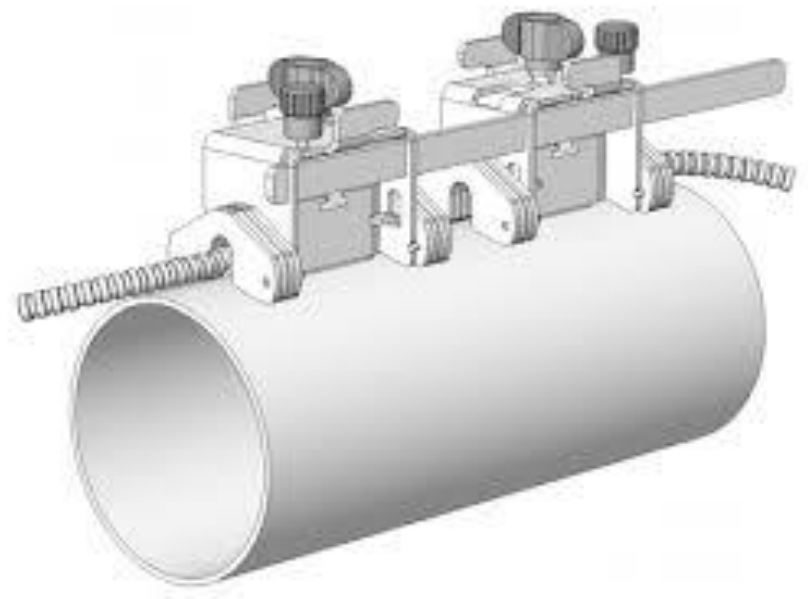

Fig. 2. Mounting of the FLEXIM sensors on the pipe surface using fastening shoes [16]

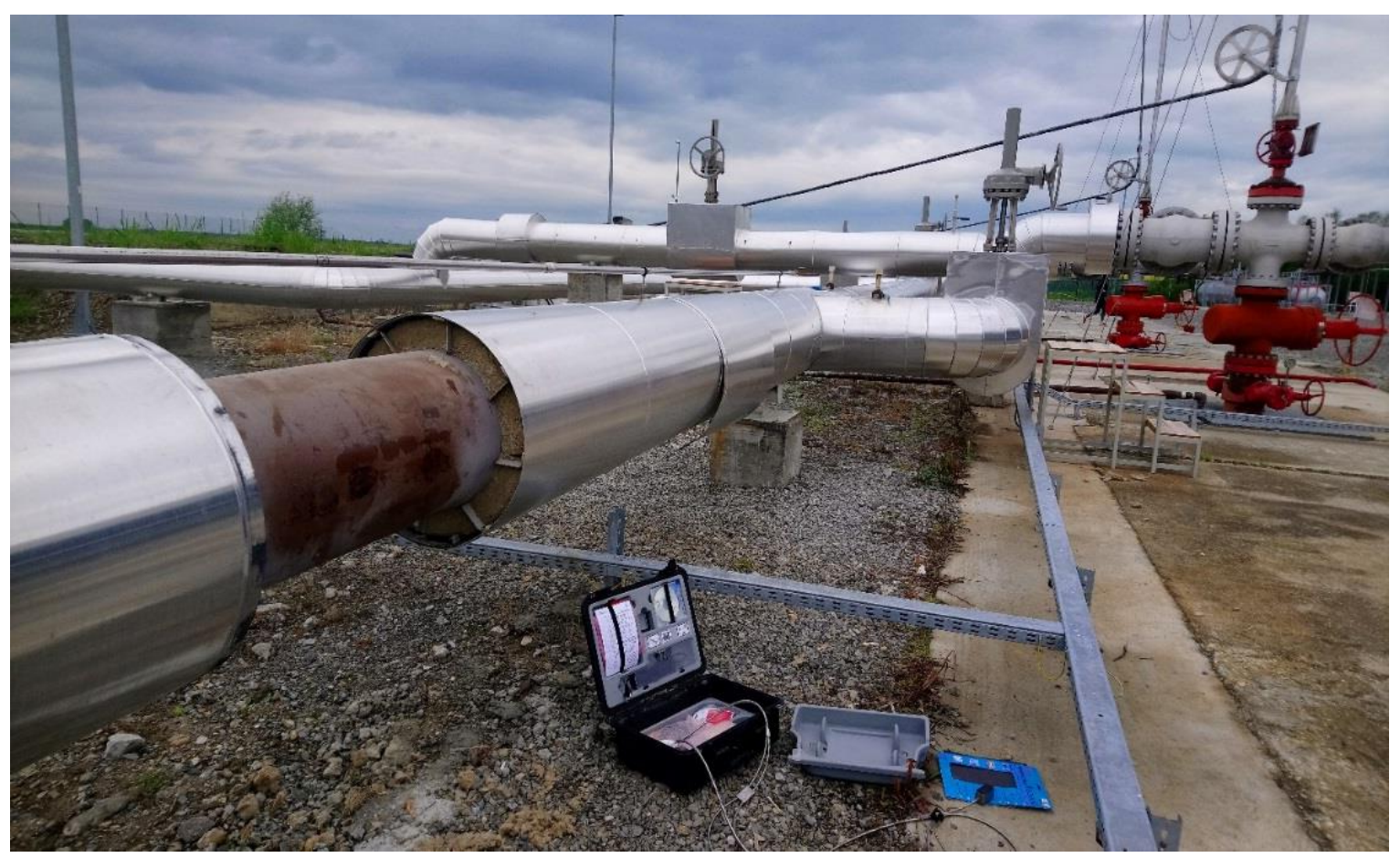

Fig. 3. Measurement point at the well outlet pipe 


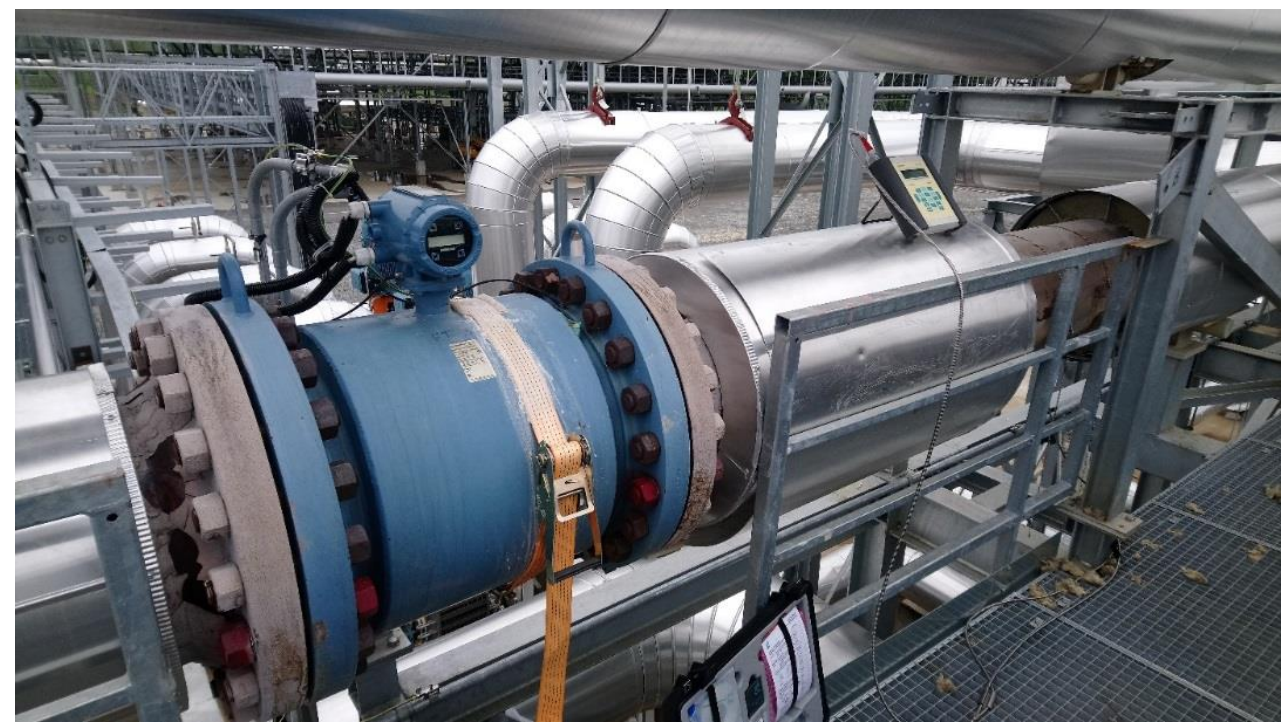

Fig. 4. Measurement point at the separator outlet pipe

Geothermal fluids and scale deposits vary considerably in composition [17]. The gaseous portions of the geothermal fluids that may contain gaseous primary fluid [18] are mixtures of steam and brine at much higher pressures [19]. Heat from the geothermal fluid is transferred to the closed cycle power plant; and heat depleted geothermal fluid is injected into a rejection well [20]. Ultrasonic flow meters have many advantages; however, there are technical limitations that make steam flow more difficult for ultrasonic flow meters [21]. A non-invasive measuring clamp-on ultrasonic [22] flow monitor F/G601 has an accuracy of $\pm 0.5 \%$. Its repeatability is $0.15 \%$ and the measuring velocity starts from $0.01 \mathrm{~m} / \mathrm{s}$ [23]. Such type of flow monitor was direct applied at the well outlet. Since the steam flow measurement using ultrasonic method is difficult, there were no results. The second measurement was done at the outlet of the separator, where the gaseous phases are separated from the water. At this point we got useful signals as shown on the Fig. 5.

\begin{tabular}{|l|c|c|}
\hline \multicolumn{1}{|c|}{ Physical quantity } & Unit & A \\
\hline Outer diameter & $\mathrm{mm}$ & 410,8 \\
\hline Pipe wall thickness & $\mathrm{mm}$ & 7,5 \\
\hline Pipe wall material & & Grey cast iron \\
\hline Roughness & $\mathrm{mm}$ & 0,3 \\
\hline Fluid & $\mathrm{m} / \mathrm{s}$ & Water \\
\hline Fluid sound speed & ${ }^{\circ} \mathrm{C}$ & 1438,64 \\
\hline Fluid temp. & & n/a \\
\hline Fluid pressure & & CDM1EZ778779 \\
\hline Transducer s/n & & 2 \\
\hline Sound paths & $\mathrm{mm}$ & 255,8 \\
\hline Transducer distance & & $\mathrm{m} / \mathrm{s}$ \\
\hline Volume units & $\mathrm{s}$ & 10 \\
\hline Damping & & yes \\
\hline Logging enabled & & last value \\
\hline Storage mode & $\mathrm{s}$ & 10 \\
\hline Storage rate & & no \\
\hline Ringbuffer & & yes \\
\hline Add. Diagnostic & & $0,025 \mathrm{~m} / \mathrm{s}$ (default) \\
\hline Cut-off flow + & & $0,025 \mathrm{~m} / \mathrm{s}$ (default) \\
\hline Cut-off flow - & & Default \\
\hline Field calibration & & \\
\hline
\end{tabular}

Table 1. Set up of the flow meter unit 


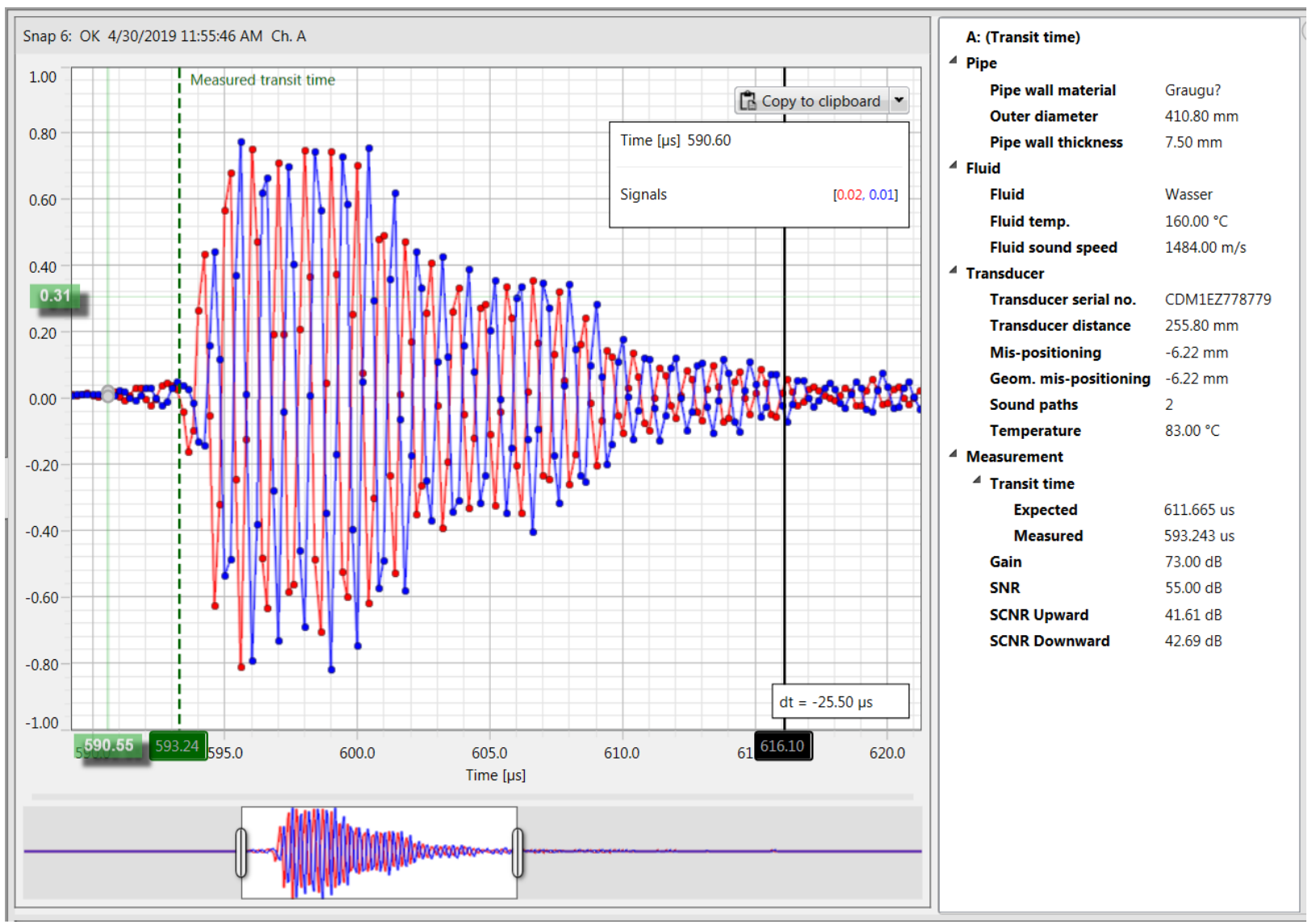

Fig. 5. Signal shape and signal quality qualification

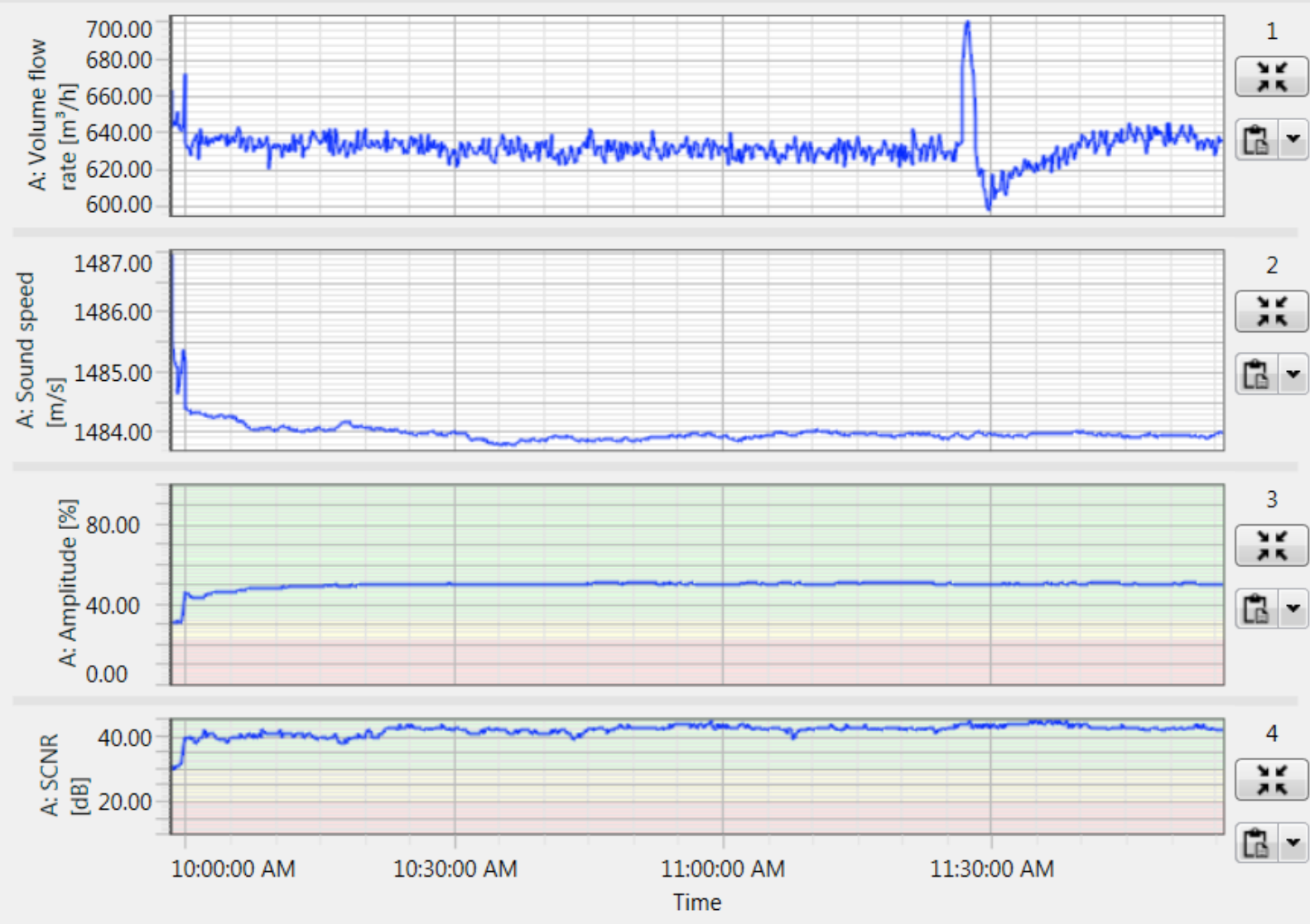

Fig. 6. Trends of media flow, sound speed of the media and the diagnostic parameters 


\section{Discussion}

System of flow measurement in technological process control requires high precision equipment to ensure reliable results [24].New generation of these flow meters will have integrated mathematical algorithms to calculate the temperature of the water inside the pipe. Water temperature monitoring, resp. changing of the temperature over the sound speed brings the advantage of the response rate to the change in the process [25]. This function provides reliable and fast values of the temperature and can eliminate or compare the temperature with another in-situ sensor as well.

In-situ flow monitors like i.e. electromagnetic ones standardly used for such application have a very complicated installation because of big dimensions a weight. Moreover, there are impurities in the medium causing problems with disturbing of internal surface or layers of solid particles. Clamp-on technology is the ideal one for such or similar applications.

\section{Future research plans}

There are still problematic process conditions for ultrasonic flow measurements directly at the outlet of the wells. The water consist of big amount of gas and the flow is very turbulent. Turbulences are not a big problem for such flow monitors because of very sophisticated mathematical algorithms implicitly integrated in the software of the flow measurement devices. Problematic is the gas which makes a very high barrier for sound going through the media. The research and development office by the producer works on solving each problem either directly or taking other way to make the measurement possible with the same device for all applications in the specific area.

There is still an invention on the field of applying ultrasound in technological processes solving such difficult applications is always a challenge for the technicians and scientists.

\section{Conclusion}

Flow monitoring using non-invasive principle is a kind of progressive measurement method for such difficult process conditions because there is no need to go into the system. Ultrasonic method is practically isolated from the process and only one important thing to be considered is the temperature of the process media. According these parameters, the sensor design must fulfil a proper temperature range. One of the advantages of this method is that clamp-on system can be used as portable and stationary version. In case of stationary versions, the location of the measurement point can be changed without mechanical modification of the pipe. Moreover, all modifications of the measurement are independent from the technology process.

This kind of measurement is an ideal solution for water flow monitoring on the geothermal water lines. There are several producers of such flow meters but such application with huge flow and pressure fluctuations and turbulent streams require quite sophisticated mathematical algorithms, signal filters, compensations and sophisticated electronics to ensure a stable and reliable result of measurement. Implementing this kind of flow measurement systems brings several advantages for technological processes, controlling systems and safety procedures as well. As mentioned above, the ultrasonic method is non-invasive measurement one and allows to perform flow monitoring without disturbing or interrupting technological process. Moreover, allows very easy positioning or changing the measurement point without almost any restrictions.

Of course, there are some limitations in the type of process media there. Gas content more than $10 \%$ in liquid, solid content higher than $10 \%$. Temperature limitation is on $230{ }^{\circ} \mathrm{C}$, using special transducer design up to $600{ }^{\circ} \mathrm{C}$. New generation of ultrasonic flow meters allow to measure steam up to $180{ }^{\circ} \mathrm{C}$ very precisely.

\section{References}

[1] Dickson, M. H.; Fanelli, M. (2013). Geothermal energy: Utilization and technology. Routledge, 224 ps. ISBN: 9781315065786

[2] Tester, J. W., et al. (2006). The future of geothermal energy. Impact of Enhanced Geothermal Systems (EGS) on the United States in the 21st Century, Massachusetts Institute of Technology, Cambridge, MA, 372.

[3] Hirtz P.N., Buck, C.L., and Kunzman, R.J. (1981). Current Techniques in Acid-Chloride Corrosion Control and Monitoring at The Geysers. Proc., Sixteenth Workshop on Geothermal Reservoir Engineering, Stanford University, Stanford, California, 83.

[4] Stockman, E.J. et al. (1993). Measuring Steam Impurities in a Geothermal Pipeline System Using Real-Time Instrumentation. Geothermal Resources Council Trans. 17: 399.

[5] SaveOnEnergy. How Geothermal Energy Works. Available from: https://www.saveonenergy.com/how-geothermalenergy-works/, Accessed: 2019-06-19

[6] ThorndonCook. Taheke Geothermal Power Plant Concept Study. Available from:https://www.thorndoncook.com/projects/taheke-geothermal-power-plant-concept-study, Accessed: 2019-0621 
[7] Králiková, R., Miháliková, R. (2009). Product life cycle management applications. - In: RIM 2009: Development and modernization of production : 7th international scientific conference : Cairo, Egypt, p. 207-208. ISBN 9789958-624-29-2

[8] Salas, R. (2009). Design of monitoring and control systems for geothermal steam for gathering systems comparision with the existing system for the miravalles geothermal field. Geothermal training programme. United Nations University in Reykjavik, Iceland

[9] IndustrialDynamics. Flow Measurement in Power Plants. Available from: http://www.industrialdynamics.com/blog/flow-measurement-in-power-plants/, Accessed: 2019-07-04

[10] Helbig, S.; Zarrouk, S. J. (2012). Measuring two-phase flow in geothermal pipelines using sharp edge orifice plates. Geothermics, 44: 52-64. ISSN 0375-6505

[11] SmartMeasurement. Doppler and Transit Time Techniques for Ultrasonic Flow Meters.Available from: https://www.smartmeasurement.com/meter-energy-ultrasonic-btu-flowmeter-flow-on-clamp-disadvantages-andadvantagesAccessed: 2019-06-19

[12] Hoheisel, G. Method and assembly for ultrasonic clamp-on flow measurement, and bodies for implementing the measurement. U.S. Patent Application No 16/251,719, 2019

[13] Scharnitzky, Jan Frederik. (2017). Measuring head clamp-on device for ultrasonic flow-measuring heads. U.S. Patent No 9,581,477.

[14] Funck, B.; Mitzkus, A. (2009). Method for calibrating ultrasound clamp-on flowmeters. U.S. Patent No 7,506,532.

[15] Industry Petrochemical; Energy, District. FLUXUS®. Available from: http://www.aquip.com.au/wpcontent/uploads/2016/12/BULIQUIDV7-1EN1.pdf, Accessed: 2019-06-19

[16] Mimos. The Portable Flowmeter. Fluxus ADM6725. Available from: http://www.mimos.si/FLEXIM/AMD6725.pdf, Accessed: 2019-07-20

[17] Gallup, D. L. (1998). Geochemistry of geothermal fluids and well scales, and potential for mineral recovery. Ore Geology Reviews, 12.4: 225-236 ps.

[18] Sheinbaum, I. (1985). Flowing geothermal wells and heat recovery systems. U.S. Patent No 4,512,155.

[19] Bronicki, L. Y., et al. (1997). Geothermal power plant operating on high pressure geothermal fluid. U.S. Patent No 5,671,601.

[20] Bronicki, L. Y. (1985). Geothermal power plant and method for operating the same. U.S. Patent No 4,542,625.

[21] FlowControl. (2010). 7 technologies for steam flow measurement. Available from: https://www.flowcontrolnetwork.com/7-technologies-for-steam-flow/, Accessed: 2019-07-20

[22] Sacher, J. A non-invasive exploitation of energy conservation potentials using ultrasonics. Non-invasive diagnostics; Mit Ultraschall eingriffsfrei Energieeinsparpotenziale erschliessen. Nichtinvasive Diagnostik. 2013. ISSN 0949166X; TRN: DE13G5586

[23] Zheng, B. et al. (2014). Experimental investigation of heat transfer characteristics of calcined petroleum coke finand-tube waste heat exchanger. The Open Fuels\&Energy Science Journal, 2014, 7.1: 20-25. ISSN: 1876-973X

[24] Wessely, E., Králiková, R., Krupa, M. (2008). Efficient management in production companies by implementation of PLM. - In: Annals of DAAAM for 2008, Vienna: DAAAM International, p.1527-1528. - ISBN 9783901509681

[25] Halper, Ch., Ilko, J. \&Rusko, M. (2018). Application of ultrasonic method for measuring the sound velocity in a medium to instantly determine the temperature change and fluctuations. Proceedings of the 29th DAAAM International Symposium, pp.0687-0697, B. Katalinic (Ed.), Publishedby DAAAM International, ISBN 978-3902734-20-4, ISSN 1726-9679, Vienna, Austria

[26] Ferencz, V., Dugas, J., Prividy, D., Andrejkovič, M., Cehlár, M. et Z. Jurkasová. (2015). The Implementation of knowledge-intensive services in drawing out and bottling of natural mineral water. In Acta montanistica slovaca: international scientific journal. Košice: Technical university of Košice, 2015. ISSN 1335-1788, 2015, vol. 20, no. 2, pp. 125-140.

[27] Zimon, D., Gajewska, T. et L. Bednárová. (2016). An influence of quality management system for improvement of logistics distribution, In: Quality - Access to Success, Bukurešt', Romania, ISSN 1582-2559, vol. 17, No.155, December 2016, pp. 68-71 